top positions that gender correction on committees is not feasible.

"I was shocked to realize that there is a factor-of-ten loss between women who join INFN at the lowest rank and those at the top," he says. He sees no obvious solution, but says the INFN is "open to all suggestions".

One concept that finds no favour is the introduction of quotas of senior slots for women scientists. "We don't want a quota for women," says Flavia Zucco, a senior researcher at the CNR Institute for Biotechnology Research in Rome. "We just want the quota for men abolished."

The findings were welcomed by European Research Commissioner Philippe Busquin, who said the study was "the first to undertake a full comparative analysis of women's careers in public research institutes". Lack of data on women's careers in research hinders attempts to resolve the problem, according to Busquin.

Mary Osborn, a researcher at the Max Planck Institute for Biophysical Chemistry in Göttingen, Germany, who helped produce the European Commission's recent report on women and science (see Nature 402, 337; 1999), sees "no single solution to the problem". She argues that the issue needs to be "tackled by all means and at all levels".

Another investigation of women's careers in Italian universities is about to start.

\title{
International search underway in Italy for institute directors
}

Italy's National Research Council (CNR) is this week breaking from its much-criticized practice of filling key posts from within its ranks, and is advertising internationally for scientists to head some of its institutes.

The positions are the first to arise under a reorganization that will combine some 300 CNR institutes and university-based centres into 95 larger units. This is the first step in a reform programme to make the CNR more efficient (see Nature 394, 712; 1998).

The appointments are for four-year renewable terms. Each new director will be responsible for coordinating research programmes at the merged centres and institutes.

Most scientists agree that the new arrangement will promote collaborative research, but say that, with no extra money available for research, it is not ideal.

Some observers are also sceptical about whether outsiders will find the new directorships attractive. For example, they will have few opportunities to build their own research teams. This is "a weakness in the process", says John Guardiola, head of

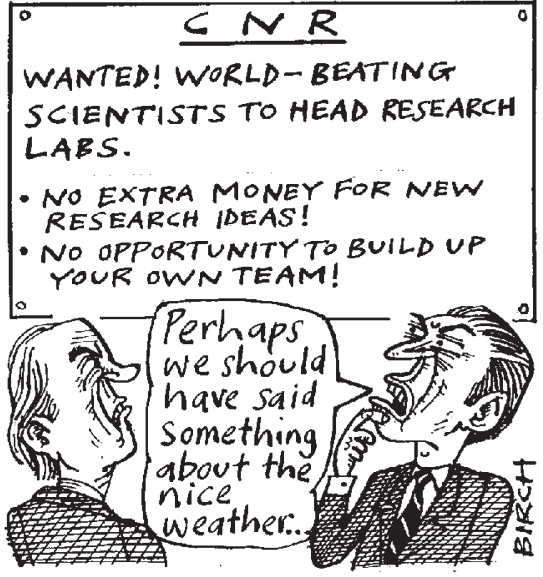

the CNR International Institute of Genetics and Biophysics in Naples.

Arturo Falaschi, the director of the International Centre for Genetic Engineering and Biotechnology in Trieste, is more optimistic. Together with an expected competition to attract 1,000 researchers, he says advertising the directorships could help to address problems such as gender imbalance. 